\title{
Effect of Job Rotation on the Risk of Developing UI-WMSDS in Poultry Slaughterhouse Workers
}

-Author(s)

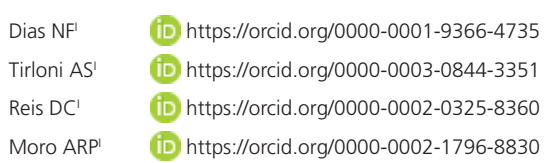

Technological Center, Federal University of Santa Catarina, SC, Brazil - Biomechanics Laboratory, CDS, Federal University of Santa Catarina, SC, Brazil.

\section{-Mail Address}

Corresponding author e-mail address Natália Fonseca Dias

Rua Prefeito Wenceslau Borini, 2073 - 303 Canta Galo, Rio do Sul, SC, 89163-062,

Brasil.

Phone: (5547) 99914-6146

Email: ergonomia.nd@gmail.com

\section{Eeywords}

Ergonomics, job rotation, musculoskeletal disorders, slaughterhouse.

\section{ABSTRACT}

This study analyzed the effect of job rotation on the risk of developing UL-WMSDs in a poultry slaughterhouse with 1,200 workers. Three organizational settings were evaluated ("without job rotation", "with job rotation - tasks $>1 \mathrm{~h}$ " and "with job rotation - tasks $<1 \mathrm{~h}$ ") using the OCRA Checklist method and the fulfillment of requirements for the implementation of rotations established by the Brazilian Regulatory Standard NR-36. The OCRA score of the right upper limbs (16.5 \pm 5.7$)$ were significantly higher $(p<0.001)$ relative to the left upper limbs (15.0 \pm 5.6$)$. The average scores on all three organizational conditions presented moderate risk. There was a significant difference between the scores of the conditions "without job rotation" and "with job rotation - tasks $<1 \mathrm{~h}$ " $(p=0.011)$, as well as "without job rotation" and "with job rotation - tasks $>1 \mathrm{~h}$ " $(p<0.001)$. Thus, the results of the risk using the OCRA Checklist method showed the inefficiency of the realization of rotations $>1 \mathrm{~h}$ and $<1 \mathrm{~h}$ compared to not carrying out job rotation for the reduction of the UL-WMSDs risk. In relation to NR36 requirements, it was found that alternating sitting and standing posture, postural requirements reduction and monotony were met by most sectors. Finally, it was difficult implementing efficient rotations due to particularities of work in the slaughterhouses such as: tasks with similar musculoskeletal requirements, pace imposed by machines, inability to perform rotations between different sectors (health and occupational constraints), the predominance of tasks with moderate and high risks, hindering the distribution of risks between the tasks of the rotation

\section{INTRODUCTION}

Brazil is the leader in the export of chicken meat in the world, and the second biggest producer of this product (ABPA, 2017). The development of work-related musculoskeletal disorders (WMSDs) are frequent in industrial task workers (Rassoto et al., 2015). The implementation of (neo-) tayloristic production principles, focusing on the elimination of time loss, modified the characteristic of the tasks, reducing the cycles of work and making the tasks repetitive and monotonous (Mathiassen, 2006). The slaughterhouses favor WMSDs development because they present ergonomic risk factors such as intense rhythm of the workday, inadequate postures, application of force for the handling of loads (Caso et al., 2007), insufficient recovery time (Punnett \& Wegman, 2004), vibrations and low temperatures (OSHA, 2013).

Slaughterhouse workers are subjected to physical demands of the upper limbs (Bernard, 1997), and according to Van der Windt et al. (2000), repetitive movement, vibration and the duration of work are risk factors for the occurrence of pain in the shoulder. The study of Tirloni et 
al. (2012) shows that $62.6 \%$ of workers surveyed from a poultry slaughterhouse felt pain in the shoulder, and the most frequent symptoms were pain, fatigue and tingling. To prevent these disorders, an organizational measure commonly used is the job rotation (Arvidsson, 2012; Huang et al., 2014; Rodriguez \& Barrero, 2017), alternating workers between two or more tasks, aiming to reduce occupational risks (Howarth et al., 2009).

The job rotation provides a distribution of workloads, balancing the effect of repetitive and monotonous work (Michalos, 2010), and giving the chance to vary the intensity of muscular activity (Rodriguez \& Barrero, 2017). Nevertheless, the benefits of this strategy about prevention and control of WMSDs was not proven (Rodriguez \& Barrero, 2017; Padula et al., 2017).

To estimate the occupational risk of WMSDs in upper limbs repetitive tasks workers, OCRA (Occupational Repetitive Actions) method is widely recognized (Colombini et al., 2002; Occhipinti et al., 2007) and recommended by regulatory standards EN 1005-5 - Risk Assessment for Repetitive Handling (CEN, 2005), by ISO 11228-3 - Handling of Low Loads at High Frequency $(I S O, 2007)$ and by the ABNT NBR ISO 11228-3 -Ergonomics - Manual handling Part 3: Handling of low loads at high frequency (ABNT, 2014).

In order to identify the risks of the tasks in a poultry slaughterhouse, Reis et al. (2016) applied the OCRA Checklist method and noted that $77 \%$ of these tasks presented moderate risk of developing upper limb work-related musculoskeletal disorders (UL-WMSDs), pointing higher probability of incidence for the right upper limb (between 10.8 and 21.5\%). Other studies have examined the risk of tasks in poultry slaughterhouses using the OCRA method (Reis et al., 2015a; Reis et al., 2015b; Reis et al., 2016; Reis et al., 2017) and found that most of the tasks were classified as moderate risks (Reis et al., 2015a; Reis et al., 2016; Reis et al., 2017) or as high risks (Reis et al., 2015b). However, these studies have analyzed the tasks individually, without rotations.

The recent implementation of the Regulatory Standard 36 (NR-36) (Brazil, 2013), which sets out the minimum requirements for evaluation, control and monitoring of risks in tasks carried out in Brazilian meat processing industries, recommends job rotation in slaughterhouses. Despite this, there is a lack of studies that verify its efficiency in slaughterhouses. Therefore, the objective of this study was to analyze the effect of job rotation on the risk of developing UL-WMSDs in a poultry slaughterhouse.

\section{MATERIALS AND METHODS}

This cross-sectional observational study was approved by the Committee of Ethics in Research with Human Beings, of the Federal University of Santa Catarina - Brazil, under 2098/2011 Protocol, in accordance with the Declaration of Helsinki.

The study was conducted in a poultry slaughterhouse in southern Brazil which slaughtered 80,000 chickens a day and had about 1,200 employees distributed over two production shifts and one cleaning shift.

\section{Participants}

The productive area of the slaughterhouse was composed of 15 sectors, and in 5 of those, workers were carrying out tasks that did not meet the NR-36 requirements, highlighting that the rotation was not performed properly. Therefore, the selection of the sectors and participants were intentional, where 10 sectors that workers performed job rotations were included in the study. The automatic line sector involved the smallest number of tasks (2), while the giblets sector had the largest number of tasks (10), totaling 41 tasks that formed 10 job rotation schemes (Table 1). The selected sectors involved processes from the arrival of poultry in the company until tasks covering the final packing of the products (Figure 1).

Rotations were comprised of different workers, at least 14 and a maximum of 36 workers participated in the rotation by sector, totaling 208 workers. Workers who performed the tasks in these sectors had ages between 18 and 64, of both genders, 51\% women and $49 \%$ men and the predominance of education was incomplete middle school.

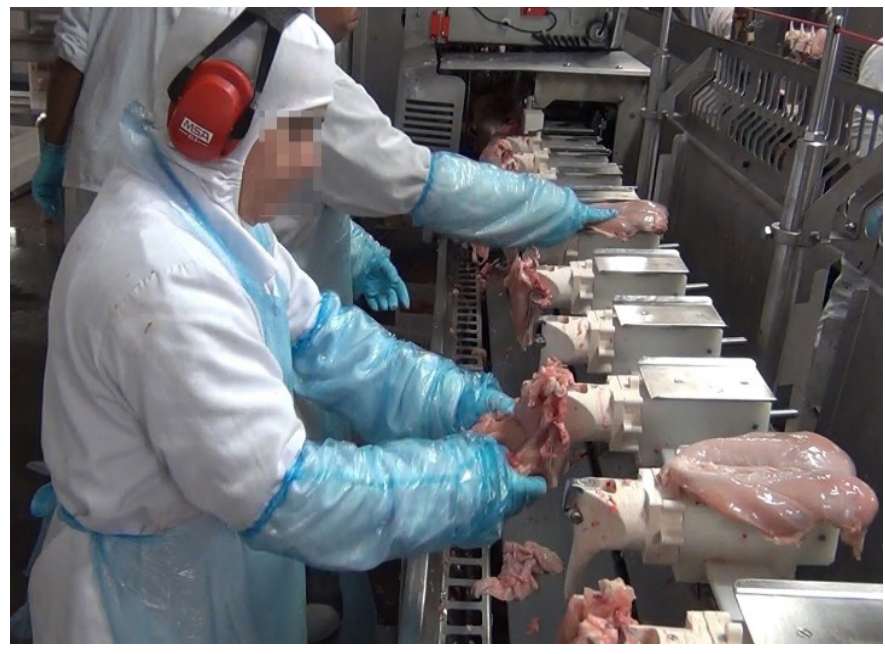

Figure 1 - Task of breast removal in deboning system sector.

As reported by Colombini et al. (2014), when there are variations in the way a task is executed, it is 
recommended to film 2 or 3 workers. In the present study, a professional of the labor safety team filmed at least $25 \%$ of the workers of each sector. However, before data acquisition, there was observational analysis of the workers of each sector. In order to verify the standardization in the execution of tasks among workers, avoiding the image captures and the analysis of disparate standards of task performance. For the application of the OCRA Checklist, the filming of only one worker per sector was used, which represented the movement pattern of the other workers of his/ her sector.

\section{Risk factors of the OCRA Method}

To analyze the risk of UL-WMSDs development, the OCRA Checklist method (Occupational Repetitive Actions) was used, which characterizes upper limb risk factors: work organization (to determine the duration multiplier factor), lack of recovery periods, repetitiveness (frequency of technical actions), force demand, inappropriate postures and movements, stereotypy, and other additional factors (Colombini et al., 2002) (Figure 2).

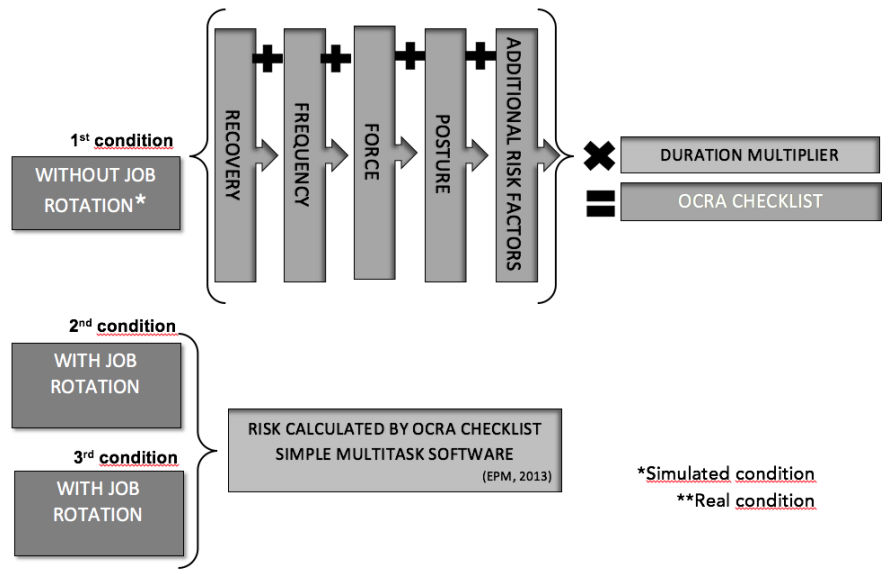

Figure $\mathbf{2}$ - Calculation of real and simulated organizational conditions of job rotations using the OCRA Checklist method in a poultry slaughterhouse

Work organization is the factor used to identify the total repetitive task time based on the total time per workday. In the OCRA Checklist, the official and unofficial pauses, time on non-repetitive tasks and the meal break are subtracted from the total time of the workday (Colombini et al., 2014). In the analyzed slaughterhouse, the total working time was 528 minutes, decreasing 60 minutes of psychophysiological breaks ( 3 intervals of $20 \mathrm{~min}$ ) and $20 \mathrm{~min}$ for uniform change (10 min after entering and 10 min before exiting the sector), totaling 448 effective min of repetitive work during the workday. In addition, there was a general 60 min meal break, not including the total time of the workday.
The effective duration of repetitive work during the workday is used to determine the duration multiplying factor, which has a score that varies from 0.5 to 1.5 (Colombini et al., 2014), and the longer the repetitive task during the workday, the greater the multiplying factor. For 448 minutes of repetitive working, the multiplying factor is one.

To classify the recovery periods, information on the distribution of breaks during the workday and the duration of each break were collected. At the analyzed slaughterhouse, three breaks of 20 min were performed in an 8 hour shift that received the threerisk classification.

For the purpose of evaluating the frequency of technical actions and the bodily postures adopted in both sides of the body in the tasks, a Sony DSCW800 camcorder was used, in which workers of each task were filmed for at least two minutes $( \pm 10$ cycles of the task). According to Colombini et al. (2014), a few cycles are sufficient to film for each repetitive tasks (3 or 4 cycles). The frequency is measured through the number of technical actions carried out per minute. Technical actions are identified by the set of movements of one or more body parts of upper limbs, which allow the execution of each work operation (Colombini et al., 2014). The higher the frequency of technical actions per minute, the higher the score of this risk factor.

The OCRA Checklist method recommends, first, to identify which technical actions in the cycle involve force; second, to question employees about the perception of the strength level for each of these technical actions of the task cycle using the Borg scale (0-10). Then, check the duration of each action (\%) in which this force is applied during the cycle (two seconds in each cycle, $1 \%, 5 \%$ or more than $10 \%$ of the time) and finally, calculate the average force score in relation to force technical actions of the cycle (Colombini et al., 2014).

In the OCRA Checklist, body posture assessment is performed individually in the joints of the shoulders, elbows, wrists and hands/fingers, being that the worker is filmed in the front and side view that allowed visualization of the two upper limbs. The posture score is given depending on the time spent in each posture of risk during the task cycle. Only the largest value among the analyzed body parts is considered in the sum of the final score, together with the stereotyped factor (Colombini et al., 2014).

For this stereotypy factor, when there are identical works gestures of the shoulder and/or elbow and/or wrist and/or hand, repeated almost the entire time, 
or the cycle time is less than 8 seconds, even with different technical actions among them, the score is classified as 3. When these same gestures are repeated during more than half of the time, or with a cycle time between 8 and 15 seconds even with different technical actions among them, the score is classified as 1.5 (Colombini et al., 2014).

Additional factors vary according to the characteristics of each task and the environment sector, which are classified into two categories: physicalmechanical aspects and organizational aspects. The physical-mechanical factors involve environmental characteristics such as temperature, inadequate tools and sudden movements, etc. Organizational factors include characteristics such as the working pace is completely determined by the machine or where there are "breathing spaces" in which the working rhythm can either be slowed down or accelerated. For every aspect framed by the task with a score of 1 to 3 is defined (Colombini et al., 2014).

\section{Job Rotation Conditions}

The job rotations performed in the analyzed slaughterhouse were established in the same year of the implementation of NR-36 (2013) by the occupational safety and health administration of the company. The application of job rotations aimed to meet the requirements of NR-36 (Brazil, 2013), besides obeying the hygienic-sanitary aspects, the workers' pay scale and the proximity between the tasks. The intervals between the tasks were organized to coincide with the times of psychophysiological breaks, i.e. when the worker returned from the break, he/she would restart working on another task.

In the present study, three conditions were analyzed, one real and two simulated (Figure 2):

$1^{\text {st }}$ condition

"without job rotation" where the tasks were analyzed individually and used the equation from the OCRA Checklist; this condition was simulated.

\section{$2^{\text {nd }}$ condition}

"with job rotation - tasks $>1 \mathrm{~h}$ ", it is the real condition of the analyzed slaughterhouse where at least one of the tasks that comprised these job rotations lasted more than one hour. All workers were trained to perform the tasks according to the procedures determined by the occupational safety team. The time workers spent on each task that formed the rotation was not homogeneous, as the number of workstations was different in each task. For this reason, many times the workers remained more than $1 \mathrm{~h}$ performing the same task.

\section{$3^{\text {rd }}$ condition}

"with job rotation - tasks $<1 \mathrm{~h}$ ", in simulated condition all the tasks lasted less than an hour.

The rotation was coordinated by the supervisor of each sector, so that the workers alternated between 2 and 4 tasks in the 448 minutes of work, according to the organization of each sector. In sectors where workers performed more than four tasks (cone and giblets), there were different job rotation schemes, which varied day-by-day, in which all workers participated. For the risk assessment in these sectors, the job rotations scheme with the highest score in the OCRA Checklist was considered (Table 1).

Risk classifications were defined according to the criteria of the OCRA Checklist method (Table 3). To obtain the scores and the risk classifications of the single tasks and job rotation conditions of each sector, the OCRA Checklist Simple Multitask software (EPM, 2013) was used. This software uses equations considering a single task, the rotations done $>1 \mathrm{~h}$ and $<1 \mathrm{~h}$ (Occhipinti et al., 2008). Thus, on risk assessment in the job rotation, the individual risks of each task were considered in proportion to the exposure time. Both upper limbs were analyzed in each task in the three studied conditions (Figure 2). The right side of the body was analyzed for all tasks that made up the rotation and subsequently, the left side, being considered as the final score of the OCRA Checklist of the side of body with the highest score.

\section{Rotation - NR-36 Requirements}

NR-36 recommends job rotations in slaughterhouses, and this must meet at least one of the following situations: (1) alternations of work positions, such as standing and sitting postures, (2) alternations of required muscle groups, (3) switching tasks without requirement of repeatability, (4) reduction of postural demands, reduction of more frequent static and dynamic efforts, (5) alternating tasks where environmental exposure is more comfortable, (6) reduction of carrying, handling and lifting of loads (mass) and (7) reduction of the monotony (Brazil, 2013). In order to evaluate the fulfillment of these requirements, subjective analysis of the tasks and workstations by videos were used, in addition to considering the variation of the scores of risk factors using the OCRA Checklist (repeatability and posture). 


\section{Statistical analysis}

A statistical analysis was performed using SPSS Statistics software, version 17.0 (SPSS Inc., Chicago, IL, USA).

The quantitative variables were expressed such as average and standard deviation, the normality of the data was tested using the Shapiro-Wilk test, while the categorical variables were expressed as absolute and relative frequencies. The paired Wilcoxon test was used to compare the results (scores) of the OCRA Checklist "without job rotation", "with job rotation tasks $>1 \mathrm{~h}$ " and "with job rotation - tasks $<1 \mathrm{~h}$ ".

Comparisons between risk ratings of tasks "without job rotation", "with job rotation - tasks $>1 \mathrm{~h}$ " and "with job rotation - tasks $<1 \mathrm{~h}$ " were performed by the Chi-square test and Fisher's Exact test.

The Spearman correlation coefficient was used to evaluate the relationship between the scores of each body joint (shoulder, elbow, wrist, hand/fingers), and the values of the OCRA Checklist "without job rotation". The statistical significance level adopted was $\mathrm{p} \leq 0.05$ for all tests.

\section{RESULTS}

The results showed that in the minority of the tasks analyzed (17\%), workers (32) used a knife and presented scores between 3 and 4 in hand posture. However, out of the 7 tasks that used a knife, most (6) featured a score for hand or wrist that was higher than the other joints, which is a predominant factor in the final outcome of the risk for body posture (Table 1).

In the OCRA Checklist, the analysis is performed on the two sides of the body, but the final score for each task considers the side of the body that presents the higher risk (value) (Colombini et al., 2014). A statistically significant difference $(p<0.001)$ was found among the results of the OCRA Checklist on the right side $(16.5 \pm 5.7)$ and the left side (15.0 \pm 5.6), and all tasks achieved higher values on the right side (Table 1).

Regarding the frequency of technical actions, workers held $41.3 \pm 14.9$ technical actions per minute and three tasks that were not scored in this risk factor were "open cages in reception of chickens" (0 action), "fuel injection machine of the whole chicken" (24 actions) and "remove wings of the cone" (22.5 actions). On the other hand, the task "remove sassami" from the fillet cutter presented the highest number of actions (76) carried out by workers in one minute (Table 1).

According to the analysis, the average scores of the OCRA Checklist presented the risk classification as moderate in the three conditions analyzed (Table 1). There was a significant difference between the scores of "without job rotation" and "with job rotation - tasks $<1 \mathrm{~h}$ " conditions ( $p=0.011)$, in addition to "without job rotation" and "with job rotation - tasks $>1 \mathrm{~h}$ " $(p<0.001)$.

The presence of identical gestures of work on the shoulder and/or elbow and/or wrist and/or hand (stereotypy) repeated almost the entire time (score 3 ) was recorded in $68 \%$ of the analyzed tasks, thus classifying the tasks as repetitive. More frequent additional factors (68\%) received a score of 2 - the work pace is completely determined by machines; only $20 \%$ received a score of 1 - the working pace is determined by the machines, but there are "breathing spaces" in which the working rhythm can either be slowed down or accelerated; $2 \%$ received a score of 3 - there are one or more additional factors that occupy almost the entire time (working pace is completely determined by machines/exposure to intense heat and humidity); and finally, $10 \%$ of tasks did not score on this risk factor (Table 1).

From the analysis by using the Fisher's Exact Test, significant differences were found between risk ratings of "without job rotation" tasks and "with job rotation - tasks $>1 \mathrm{~h}$ " $(p=0.024)$, along with "with job rotation - tasks $<1 \mathrm{~h}$ " $(p=0.005)$. As seen in Table 1, for most of the tasks, the risk level was kept "with job rotation - tasks $>1 \mathrm{~h}$ " $(\mathrm{n}=22-54 \%)$ and "with job rotation - tasks < $1 \mathrm{~h}$ " ( $n=25-61 \%)$ when compared to the condition "without job rotation". However, $44 \%$ of the tasks had an increased risk in the condition "with job rotation - tasks $>1 \mathrm{~h}$ " and $29 \%$ of the tasks "with job rotation - tasks $<1 \mathrm{~h}$ ". Besides, only $2 \%$ of the tasks had a decreased risk "with job rotation - tasks $>1 \mathrm{~h}$ " and $10 \%$ of the tasks "with job rotation - tasks $<1 \mathrm{~h}$ ". There was a difference between the number of cases of the risk rating of the job rotations $<1 \mathrm{~h}$ and $>1 \mathrm{~h}(p=0.016)$, since $39 \%$ of the tasks classified as high risk in the work real condition of the slaughterhouse workers (tasks $>1 \mathrm{~h}$ ), they were changed to moderate risk in the simulation of job rotation $<1 \mathrm{~h}$.

With respect to the assessment of body posture, most of the tasks received a score of 1 for the shoulder $(56 \%)$, a score of 2 for the elbow (68\%) and wrist 
Table 1 - Description of the risk assessment of the tasks using the OCRA Checklist method in three organizational conditions: "without job rotation", "with job rotation - tasks $>1 \mathrm{~h}$ " e "with job rotation - tasks $<1 \mathrm{~h}$ "

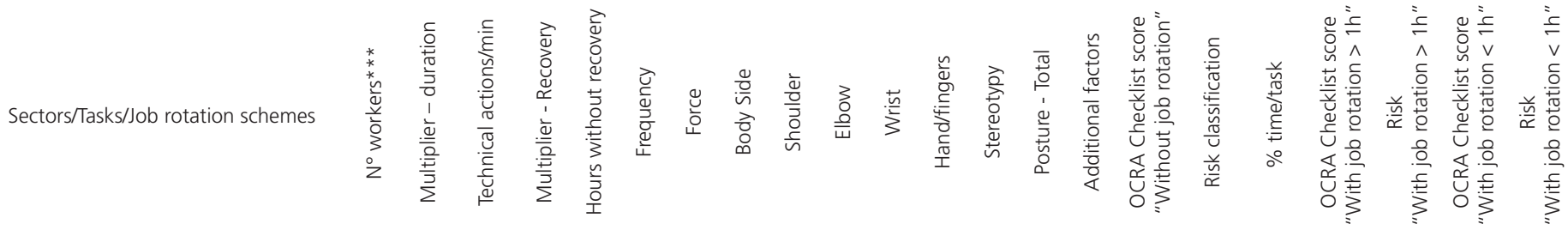

\begin{tabular}{|c|c|c|c|c|c|c|c|c|c|c|c|c|c|c|c|c|c|c|c|c|c|c|}
\hline Reception of chickens & & & & & & & & & & & & & & & & & & & & & & \\
\hline Unloading cages & 4 & 1 & 36 & 1.2 & 3 & 3 & 4 & $R$ & 2 & 2 & 3 & 3 & 3 & 6 & 1 & 16.8 & 3 & 13.0 & 19.1 & 3 & 17.6 & 3 \\
\hline Open cages & 2 & 1 & 0 & 1.2 & 3 & 0 & 0 & $\mathrm{R}$ & 1 & 0 & 0 & 0 & 0 & 1 & 0 & 1.2 & 0 & 7.0 & 19.1 & $3^{* *}$ & 17.6 & $3^{* *}$ \\
\hline Hanging chickens & 18 & 1 & 42 & 1.2 & 3 & 4 & 3 & $\mathrm{R}$ & 4 & 2 & 4 & 3 & 3 & 7 & 2 & 19.2 & 3 & 80.0 & 19.1 & 3 & 17.6 & 3 \\
\hline Scalding & & & & & & & & & & & & & & & & & & & & & & \\
\hline Chicken paws screening & 2 & 1 & 60 & 1.2 & 3 & 8 & 0 & $\mathrm{R}$ & 1 & 2 & 2 & 4 & 3 & 7 & 2 & 20.4 & 3 & 33.3 & 19.7 & 3 & 18.4 & 3 \\
\hline Re-hanging chicken - post-plucker & 2 & 1 & 41 & 1.2 & 3 & 4 & 2 & $\mathrm{R}$ & 4 & 4 & 2 & 4 & 3 & 7 & 3 & 19.2 & 3 & 33.3 & 19.7 & 3 & 18.4 & 3 \\
\hline Re-hanging chicken - post-transfer \# & 2 & 1 & 33 & 1.2 & 3 & 2 & 2 & $\mathrm{R}$ & 4 & 2 & 2 & 3 & 3 & 7 & 2 & 15.6 & 3 & 33.3 & 19.7 & 3 & 18.4 & 3 \\
\hline Evisceration & & & & & & & & & & & & & & & & & & & & & & \\
\hline Hanging chicken entrails & 12 & 1 & 40 & 1.2 & 3 & 4 & 0 & $\mathrm{R}$ & 1 & 1 & 2 & 4 & 3 & 7 & 2 & 15.6 & 3 & 43 & 16.3 & 3 & 15.3 & 3 \\
\hline Chicken gizzard screening & 4 & 1 & 45 & 1.2 & 3 & 5 & 0 & $\mathrm{R}$ & 1 & 2 & 2 & 4 & 3 & 7 & 2 & 16.8 & 3 & 14 & 16.3 & 3 & 15.3 & 3 \\
\hline Chicken screening & 12 & 1 & 32 & 1.2 & 3 & 1 & 2 & $\mathrm{R}$ & 2 & 2 & 2 & 3 & 3 & 6 & 2 & 14.4 & 3 & 43 & 16.3 & 3 & 15.3 & 3 \\
\hline Automatic line & & & & & & & & & & & & & & & & & & & & & & \\
\hline Re-hanging chicken & 12 & 1 & 64.3 & 1.2 & 3 & 9 & 4 & $\mathrm{R}$ & 2 & 4 & 4 & 4 & 3 & 7 & 2 & 26.4 & 4 & 86 & 26.3 & 4 & 24.6 & 4 \\
\hline Filling the conveyor belt - cone & 2 & 1 & 34 & 1.2 & 3 & 2 & 2 & $\mathrm{R}$ & 2 & 2 & 2 & 2 & 3 & 5 & 2 & 13.2 & 2 & 14 & 26.3 & $4^{* *}$ & 24.6 & $4^{* *}$ \\
\hline Whole chicken & & & & & & & & & & & & & & & & & & & & & & \\
\hline Insert chicken entrails & 4 & 1 & 54 & 1.2 & 3 & 7 & 2 & $\mathrm{R}$ & 1 & 2 & 4 & 4 & 1.5 & 5.5 & 2 & 19.8 & 3 & 33.3 & 19.8 & 3 & 16.0 & 3 \\
\hline Packing chickens & 2 & 1 & 36 & 1.2 & 3 & 4 & 2 & $\mathrm{R}$ & 1 & 2 & 2 & 2 & 3 & 5.0 & 2 & 15.6 & 3 & 16.7 & 19.8 & 3 & 16.0 & 3 \\
\hline Seal packaging chickens & 2 & 1 & 60 & 1.2 & 3 & 8 & 2 & $\mathrm{R}$ & 1 & 2 & 2 & 4 & 3 & 7.0 & 2 & 22.8 & 4 & 16.7 & 19.8 & $3^{*}$ & 16.0 & $3^{*}$ \\
\hline Filling seasoning injection machine & 4 & 1 & 24 & 1.2 & 3 & 0 & 2 & $\mathrm{R}$ & 1 & 2 & 2 & 2 & 1.5 & 3.5 & 2 & 9.0 & 1 & 33.3 & 19.8 & $3^{* *}$ & 16.0 & $3^{* *}$ \\
\hline Cone & & & & & & & & & & & & & & & & & & & & & & \\
\hline Filling cone & 2 & 1 & 30 & 1.2 & 3 & 1 & 2 & $\mathrm{R}$ & 2 & 2 & 2 & 2 & 3 & 5 & 2 & 12.0 & 2 & 25.0 & 16.4 & $3^{* *}$ & 15.3 & $3^{* *}$ \\
\hline Scratching legs \# & 2 & 1 & 30 & 1.2 & 3 & 1 & 2 & $\mathrm{R}$ & 2 & 2 & 2 & 3 & 3 & 6 & 2 & 13.2 & 2 & 25.0 & 16.4 & $3^{* *}$ & 15.3 & $3^{* *}$ \\
\hline Remove legs \#1 & 4 & 1 & 30 & 1.2 & 3 & 1 & 4 & $\mathrm{R}$ & 2 & 2 & 4 & 4 & 1.5 & 5.5 & 2 & 15.5 & 3 & 25.0 & 16.4 & 3 & 15.3 & 3 \\
\hline Remove wings \# 1 & 4 & 1 & 22.5 & 1.2 & 3 & 0 & 4 & $\mathrm{R}$ & 2 & 2 & 4 & 4 & 1.5 & 5.5 & 2 & 13.8 & 2 & 25.0 & 16.4 & $3^{* *}$ & 15.3 & $3^{* *}$ \\
\hline Remove breast and chest skin ${ }^{1}$ & 4 & 1 & 30 & 1.2 & 3 & 1 & 6 & $\mathrm{R}$ & 2 & 1 & 2 & 4 & 1.5 & 5.5 & 2 & 17.4 & 3 & 25.0 & 16.4 & 3 & 15.3 & 3 \\
\hline Remove sassami \# 1 & 4 & 1 & 37.5 & 1.2 & 3 & 3 & 2 & $\mathrm{R}$ & 1 & 1 & 2 & 4 & 1.5 & 5.5 & 2 & 15.0 & 3 & 25.0 & 16.4 & 3 & 15.3 & 3 \\
\hline Deboning system & & & & & & & & & & & & & & & & & & & & & & \\
\hline Filling deboning system & 12 & 1 & 57 & 1.2 & 3 & 7 & 4 & $\mathrm{R}$ & 1 & 2 & 2 & 4 & 3 & 7 & 2 & 24.0 & 4 & 33.3 & 24.9 & 4 & 24.4 & 4 \\
\hline Remove breast & 12 & 1 & 57 & 1.2 & 3 & 7 & 4 & $\mathrm{R}$ & 1 & 2 & 4 & 4 & 3 & 7 & 2 & 24.0 & 4 & 33.3 & 24.9 & 4 & 24.4 & 4 \\
\hline Remove sassami \# & 12 & 1 & 76 & 1.2 & 3 & 10 & 2 & $\mathrm{R}$ & 1 & 2 & 2 & 4 & 3 & 7 & 2 & 25.2 & 4 & 33.3 & 24.9 & 4 & 24.4 & 4 \\
\hline Fillet export & & & & & & & & & & & & & & & & & & & & & & \\
\hline Interfold fillet & 20 & 1 & 60 & 1.2 & 3 & 8 & 2 & $R$ & 1 & 2 & 2 & 4 & 3 & 7 & 0 & 20.4 & 3 & 83.4 & 20.3 & 3 & 18.9 & 3 \\
\hline Filling trays & 2 & 1 & 36 & 1.2 & 3 & 2 & 0 & $\mathrm{R}$ & 1 & 2 & 2 & 3 & 3 & 6 & 0 & 9.6 & 1 & 8.3 & 20.3 & $3^{* *}$ & 18.9 & $3^{* *}$ \\
\hline Interfold plastics & 2 & 1 & 36 & 1.2 & 3 & 2 & 0 & $\mathrm{R}$ & 1 & 2 & 2 & 6 & 3 & 9 & 0 & 14.4 & 3 & 8.3 & 20.3 & 3 & 18.9 & 3 \\
\hline Giblets & & & & & & & & & & & & & & & & & & & & & & \\
\hline Filling gizzard tray & 2 & 1 & 28 & 1.2 & 3 & 1 & 0 & $\mathrm{R}$ & 1 & 2 & 2 & 3 & 1.5 & 4.5 & 1 & 7.8 & 1 & 25 & 24.8 & $4^{* *}$ & 21.9 & $3^{* *}$ \\
\hline Weigh gizzard tray & 2 & 1 & 28 & 1.2 & 3 & 1 & 2 & $\mathrm{R}$ & 1 & 2 & 2 & 3 & 1.5 & 4.5 & 1 & 10.2 & 1 & 25 & 24.8 & $4^{* *}$ & 21.9 & $3^{* *}$ \\
\hline Liver screening ${ }^{1}$ & 2 & 1 & 52 & 1.2 & 3 & 6 & 2 & $\mathrm{R}$ & 1 & 1 & 2 & 4 & 3 & 7 & 1 & 19.2 & 3 & 25 & 24.8 & $4^{* *}$ & 21.9 & 3 \\
\hline Filling liver tray & 2 & 1 & 28 & 1.2 & 3 & 1 & 0 & $R$ & 1 & 2 & 2 & 3 & 1.5 & 4.5 & 1 & 7.8 & 1 & 25 & 24.8 & $4^{* *}$ & 21.9 & $3^{* *}$ \\
\hline Weigh liver & 2 & 1 & 32 & 1.2 & 3 & 1 & 2 & $\mathrm{R}$ & 1 & 2 & 2 & 3 & 1.5 & 4.5 & 1 & 10.2 & 1 & 25 & 24.8 & $4^{* *}$ & 21.9 & $3^{* *}$ \\
\hline Heart screening and packing ${ }^{1}$ & 2 & 1 & 52 & 1.2 & 3 & 6 & 0 & $\mathrm{R}$ & 1 & 2 & 2 & 4 & 3 & 7 & 1 & 16.8 & 3 & 25 & 24.8 & $4^{* *}$ & 21.9 & 3 \\
\hline Feet screening ${ }^{1}$ & 2 & 1 & 68 & 1.2 & 3 & 10 & 2 & $\mathrm{R}$ & 2 & 3 & 4 & 6 & 3 & 9 & 2 & 27.6 & 4 & 25 & 24.8 & 4 & 21.9 & $3^{*}$ \\
\hline Feet packing & 2 & 1 & 38 & 1.2 & 3 & 3 & 4 & $\mathrm{R}$ & 1 & 1 & 2 & 4 & 1.5 & 5.5 & 1 & 16.2 & 3 & 25 & 24.8 & $4^{* *}$ & 21.9 & 3 \\
\hline Shank screening ${ }^{1}$ & 2 & 1 & 56 & 1.2 & 3 & 7 & 2 & $\mathrm{R}$ & 2 & 3 & 4 & 6 & 3 & 9 & 2 & 24.0 & 4 & 25 & 24.8 & 4 & 21.9 & $3^{*}$ \\
\hline Filling machine with packs of entrails & 4 & 1 & 30 & 1.2 & 3 & 1 & 0 & $\mathrm{R}$ & 2 & 1 & 2 & 4 & 3 & 7 & 2 & 12.0 & 2 & 25 & 24.8 & $4^{* *}$ & 21.9 & $3^{* *}$ \\
\hline Legs & & & & & & & & & & & & & & & & & & & & & & \\
\hline Interfold right leg & 12 & 1 & 58 & 1.2 & 3 & 8 & 2 & $\mathrm{R}$ & 6 & 2 & 3 & 4 & 3 & 9 & 2 & 25.2 & 4 & 54.5 & 24.6 & 4 & 21.3 & $3^{*}$ \\
\hline Rework\# & 4 & 1 & 34 & 1.2 & 3 & 2 & 2 & $\mathrm{R}$ & 2 & 1 & 3 & 4 & 3 & 7 & 2 & 15.6 & 3 & 18 & 24.6 & $4^{* *}$ & 21.3 & 3 \\
\hline Filling trays & 2 & 1 & 45 & 1.2 & 3 & 5 & 2 & $\mathrm{R}$ & 2 & 2 & 2 & 4 & 1.5 & 5.5 & 2 & 17.4 & 3 & 18.2 & 24.6 & $4^{* *}$ & 21.3 & 3 \\
\hline Filling leg machine & 4 & 1 & 40 & 1.2 & 3 & 3 & 2 & $\mathrm{R}$ & 1 & 1 & 2 & 4 & 3 & 7 & 2 & 16.8 & 3 & 9.1 & 24.6 & $4^{* *}$ & 21.3 & 3 \\
\hline Average & 208 & 1.0 & 41.3 & 1.2 & 3.0 & 3.9 & 2.0 & - & 1.7 & 1.9 & 2.4 & 3.6 & 2.5 & 6.2 & 1.6 & 16.5 & 3 & 29.3 & 21.4 & 3 & 19.3 & 3 \\
\hline Standard-deviation & & 0.0 & 14.9 & 0.0 & 0.0 & 3.0 & 1.5 & - & 1.1 & 0.7 & 0.9 & 1.1 & 0.8 & 1.5 & 0.7 & 5.7 & 1.0 & 18.2 & 3.6 & 0.5 & 3.2 & 0.3 \\
\hline
\end{tabular}

* Risk in relation to the OCRA Checklist result "without job rotation" decreased

** Risk in relation to the OCRA Checklist result "without job rotation" increased

*** Total of workers in both shifts

\#Tasks in which workers used knife

${ }^{1}$ Tasks that made up the job rotation with the highest value of the OCRA Checklist result

Body Sides: $\mathrm{R}$ - right; $\mathrm{L}$ - left

Risk classification of OCRA Checklist: 0 - Acceptable, 1 - Borderline or very low, 2 - Low, 3 - Moderate, 4 - High 
(71\%) and a score of 4 for the hand/fingers (56\%) (Table 2).

Table 2 - Classification of postures for the region of the shoulder, elbow, wrist and hand/fingers according to the OCRA Checklist score.

\begin{tabular}{lcccc}
\hline $\begin{array}{l}\text { Posture Score } \\
\text { OCRA } \\
\text { Checklist }\end{array}$ & \multicolumn{4}{c}{ Region [n (\%)] } \\
\cline { 2 - 5 } & Shoulder & Elbow & Wrist & Hand/fingers \\
\cline { 2 - 5 } 0 & $0(0)$ & $1(3)$ & $1(3)$ & $1(3)$ \\
1 & $23(56)$ & $8(19)$ & 0 & 0 \\
2 & $14(34)$ & $28(68)$ & $29(71)$ & $4(10)$ \\
3 & 0 & $2(5)$ & $3(7)$ & $10(24)$ \\
4 & $3(7)$ & $2(5)$ & $8(19)$ & $23(56)$ \\
6 & $1(3)$ & 0 & 0 & $3(7)$ \\
\hline
\end{tabular}

When performing the Spearman correlation between the score of the postures and the result of the OCRA Checklist "without job rotation", there was a positive correlation for the joints of the elbow $(r=$ $0.469 ; p=0.002)$, wrist $(r=0.564 ; p<0.001)$ and hand/ fingers $(r=0.671 ; p<0.001)$.
Most tasks were classified as moderate risk in the three organizational working conditions (Table 3). Consequently, these workers have a probability of developing UL-WMSDs between 10.8 and $21.5 \%$.

Classifying the tasks individually in the five risk categories proposed by OCRA, it was found that most tasks were classified as moderate risk (51\%) and only one task was classified in the category of acceptable, noting that $70 \%$ of workers were exposed to high and moderate ergonomic risks in the upper limbs (Table 3). Analyzing the conditions of job rotations, 54\% "with job rotation - tasks $>1 \mathrm{~h}$ " and $88 \%$ "with job rotation - tasks $<1 \mathrm{~h}$ " also received high and moderate classifications.

As for the attendance of at least one of the requirements necessary for the deployment of job rotations (Brazil, 2013), it was found that alternating sitting and standing postures, postural requirements and monotony reduction were met by most sectors, and half of the sectors met the reduction of carrying, handling and lifting of loads (mass). It is observed that

Table 3 - Risk assessment of repetitive upper limb movements performed by poultry slaughterhouse workers, under three organizational working conditions

\begin{tabular}{|c|c|c|c|c|c|c|}
\hline \multirow{2}{*}{ Color } & \multirow{2}{*}{ Risk } & \multirow{2}{*}{ OCRA Checklist score } & \multirow{2}{*}{ Incidence of UL-WMSDs (\%) } & \multicolumn{3}{|c|}{$\begin{array}{c}\text { Classification of the tasks } \\
{[\mathrm{n}(\%)]}\end{array}$} \\
\hline & & & & $\begin{array}{l}\text { Without job } \\
\text { rotation }\end{array}$ & $\begin{array}{l}\text { Job rotation - } \\
\text { tasks }>1 \mathrm{~h}\end{array}$ & $\begin{array}{l}\text { Job rotation - } \\
\text { tasks }<1 \mathrm{~h}\end{array}$ \\
\hline Green & Acceptable & $<7.5$ & $<5.3$ & $1(3)$ & 0 & 0 \\
\hline Yellow & Borderline or very low & $7.6-11$ & $5.3-8.4$ & $6(15)$ & 0 & 0 \\
\hline Light red & Low & $11.1-14$ & $8.4-10.8$ & $5(12)$ & 0 & 0 \\
\hline Dark red & Moderate & $14.1-22.5$ & $10.8-21.5$ & $21(51)$ & $22(54)$ & $36(88)$ \\
\hline Purple & High & $>22.5$ & $>21.5$ & $8(19)$ & $19(46)$ & $5(12)$ \\
\hline
\end{tabular}

no sector has met the requirements related to the alternating muscle groups requested; the switching with tasks without requirements of repeatability and alternating with more comfortable environmental exposures; as well as the reduction of static and dynamic efforts (Table 4).

\section{DISCUSSION}

Although the present study covers a few tasks that used a knife, it was found that most of these tasks presented a higher rating for the posture of the anatomical segment hand/fingers compared with the other joints examined. Regardless of the automation of many processes that occurred, a large number of complaints of pain related to the ends of the upper limbs is reported by slaughterhouse workers, with a higher incidence among workers who use knives (Christensen et al., 2000). The use of knives is often associated with the emergence of UL-WMSDs (Toulouse \& Richard, 2006).

Cutting tasks require significant efforts of flexion and extension of the wrist (Arvidsson et al., 2012), maintenance of a firm grip (Colombini et al., 2014), and application of force (Buckle, 1997), indicating a relationship of physical work load and UL-WMSDs. To reduce the biomechanical stress in cutting tasks, workers should receive customized training on knife sharpening, and how to maintain the quality of the cut (Tirloni et al., 2012; Claudon \& Marsot, 2006).

Corroborating with the results of the present study, several studies in poultry slaughterhouses presented moderate risk to most tasks (Reis et al., 2017; Reis et al., 2015b). Similarly, these studies have also shown that the right upper limb of workers is subjected to a greater exposure to the risk of UL-WMSDs. 
Table 4 - Identification of the company's sectors that met the requirements of the Regulatory Standard 36 for the implementation of rotation.

\begin{tabular}{|c|c|c|c|c|c|c|c|c|c|c|c|}
\hline & \multirow[b]{2}{*}{ Requirements of Regulatory Standard 36} & \multicolumn{10}{|c|}{ Sectors } \\
\hline & & 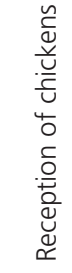 & 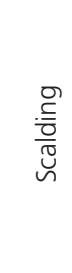 & 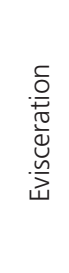 & 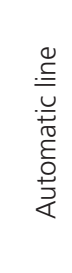 & 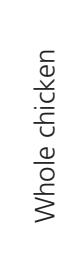 & 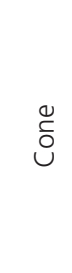 & 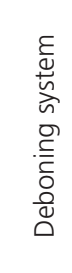 & 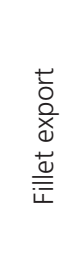 & $\frac{\frac{a}{0}}{\frac{0}{0}}$ & $\underset{\mathscr{J}}{\widetilde{J}}$ \\
\hline 1 & Postural alternating (sitting/standing postures) & & & $x$ & & $x$ & $x$ & & $x$ & $x$ & $x$ \\
\hline 2 & Alternating the muscular groups requested & & & & & & & & & & \\
\hline 3 & Alternating tasks without repeatability requirements & & & & & & & & & & \\
\hline 4 & Reducing postural requirements & $x$ & $x$ & $x$ & $x$ & $x$ & $x$ & & $x$ & $x$ & $x$ \\
\hline 5 & Reduction of more frequent static and dynamic efforts & & & & & & & & & & \\
\hline 6 & Alternating tasks which environmental exposure is more comfortable & & & & & & & & & & \\
\hline 7 & Reduction of carrying, handling and lifting of loads (mass) & $x$ & & & & $x$ & & & $x$ & $x$ & $x$ \\
\hline 8 & Reduction of monotony & $x$ & $x$ & $x$ & $x$ & $x$ & $x$ & $x$ & $x$ & $x$ & $x$ \\
\hline
\end{tabular}

According to the classification level of risk and incidence of musculoskeletal disorders, the moderate risk presents a predisposition of 10.76 to $21.51 \%$ to develop UL-WMSDs (Colombini etal., 2014). Colombini \& Occhipinti (2004) conducted a study of biomechanical overload of upper limbs in workers from various industries, including clinical and laboratory exams, finding similar results in a poultry slaughterhouse, with an average of 20 points (moderate risk) on the OCRA Checklist, confirming that $22.4 \%$ of the 969 workers were affected by UL-WMSDs.

The frequency of technical actions carried out by workers in poultry slaughterhouses is very high, considering that studies report data of $64.4 \pm 16.1$ actions per minute (Reis et al., 2017), $59.1 \pm 8.0$ per minute (Reis et al., 2016) and $63.7 \pm 25.3$ per minute (Reis et al., 2015b), representing 9, 8 and 9 points, respectively, according to the frequency range of the OCRA method (from 0 to 10 points). However, in this study, the frequency of technical actions has been classified with 4 points $(41.3 \pm 14.9$ actions per minute).

Repetitive task is characterized by the working cycle of less than 30 seconds (Konz, 1990), or more than $50 \%$ of the cycle time involved performing the same type of instrumental cycles (Silverstein et al., 1986). Colombini et al. (2014) define a repetitive task when there are distinct cycles of work, regardless of duration, performed by the upper limbs or when the repetition of the same gesture occurs during more than half of the time.

In regards to the stereotypy of the OCRA Checklist method, $68 \%$ of the tasks analyzed received a score of 3 due to the fact that the work cycle was less than
8 seconds or repeated identical movements during almost the entire cycle. On the other hand, $29 \%$ of the tasks received a score of 1.5, presenting the work cycle between 8 and 15 seconds, or by having repeated identical movements during more than half of the cycle. Therefore, this fact highlights the repetitiveness of the analyzed tasks.

In order to prevent UL-WMSDs, a worker must not exceed 25-33 movements per minute (Kilbom, 1994), allowing the proper physiological recovery. On the OCRA Checklist, this risk factor receives a zero score when it runs less than 30 actions per minute for the classification (Colombini et al., 2014). The average of technical actions per minute of the 41 tasks was $41.3 \pm$ 14.9, above the ideal amount, causing biomechanical overload and enabling the emergence of UL-WMSDs.

Mathiassen (2006) points out an industrial trend guided to implement (neo-) tayloristic productive principles, with a focus on eliminating wasted time. This production characteristic is experienced in poultry slaughterhouses, with fast production processes and tasks with short cycles. The organizational aspect, including additional factors, most evident in the tasks of this sector is the work pace completely determined by machines (68\%), justifying the model that emphasizes the reduction of wasted time.

The highest scores for the body posture on the OCRA Checklist occurred in the elbow, hand and wrist, which have a significant positive correlation with the final scores of this method. Furthermore, a study with 290 poultry slaughterhouse workers indicated that the shoulder was the region reported by the workers with the most discomfort (62.6\%), followed by the neck (46.2\%), spine (36.4\%), forearm (31.3\%), 
arm (29.2\%), wrist (25.6\%) and hand (25.6\%), with $67.2 \%$ feeling discomfort in at least one region of the body (Tirloni et al., 2012). Reis et al. (2012) conducted a study with 90 poultry slaughterhouse workers, also noting that the regions with the most discomfort were, in order, shoulder (45\%), neck (29\%), spine $(26 \%)$, arms $(23 \%)$, wrists and hands (20\%). Considering that both studies predate the implementation of NR36 , the results of this study can evidence possible improvements implemented in the workplace related to the reduction of biomechanical overload on the shoulder.

Job rotation is proposed aiming to reduce the exposure to risk factors. Nevertheless, even though researches on job rotation are limited, studies show that the desired efficiency is not always reached (Toulouse \& Richard, 2006). As for the length of the rotation interval, it was found that the task intervals interfered with the risk classification of developing UL-WMSDs, because the risk was greater when the intervals were longer than one hour.

Although the efficiency of the job rotations for the prevention of UL-WMSDs in the manufacturing industry is not unanimous among the researchers (Padula et al., 2017; Frazer et al., 2003), other psychosocial factors such as work satisfaction and engagement are shown to be improved (Zawiah \& Taha, 2007). Applying questionnaires on work satisfaction and organization, a study with 170 employees of two automotive industries found that more than $70 \%$ of employees were satisfied with the organizational conditions of job rotations (Zawiah \& Taha, 2007).

The organization of schedules to perform efficient job rotation is a complex factor due to the criteria to be considered, such as: variation of muscle groups used, reduction of frequency, reduction of boredom and monotony, besides the individual factors of each industry (Asensio-Cuesta et al., 2012). Using a lactic acid indicator to determine muscle fatigue, Filus \& Okimorto (2012) determined the interval between the job rotations in an assembly line, noting that $1 \mathrm{~h}$ and $2 \mathrm{~h}$ intervals produce less lactic acid than longer intervals.

A footwear industry initially implemented job rotations every $2 \mathrm{~h}$. However, after adjustments, the rotation was stipulated by the workers themselves in $1.5 \mathrm{~h}$, to prevent the emergence of fatigue or boredom (Guimarães et al., 2012). The monotony can be set as a property of the task or job, characterized by lack of variety or intense repeatability (Game, 2017). The analyzed tasks were classified as repetitive and met the requirement of NR-36 to reduce monotony, considering that there was motion variation.
There are many difficulties for job rotation implementation, including lack of efficient training, workstations badly designed for anatomical characteristics of workers and inefficient organizational management (Toulouse \& Richard, 2006). Despite the job rotation included in the study met the NR-36 requirements, results showed that most of the risks remained the same in the examined organizational conditions.

One justification for the inefficiency of the two job rotation conditions in reducing the prevalence of ULWMSDs is the absence of non-repetitive tasks involved in the job rotation schemes of the slaughterhouse studied. Additionally, due to the large number of moderate- and high- risk tasks as opposed to the low number of acceptable, very low- and low- risk classifications, to balance the job rotation scheme. Thus, an alternative to making task rotations efficient is to include non-repetitive tasks and/or repetitive tasks with lower risks.

As in the present study, all the sectors that performed job rotations were included, slowing down the work pace is a practical solution that lowers the individual task risks, or through the inclusion of more workers on the production line or the deceleration of the productive process (i.e. machine deceleration). However, the recommendation is to not neglect the space needed to safely perform a task, especially with the use of cutting tools. It is also suggested to improve the reaching areas to reduce inappropriate postures, as well as include short breaks each hour of the workday.

Therefore, it is considered that the implementation of rotations must be linked to other risk management measures present in the tasks, prioritizing its elimination, followed by minimization and control through administrative and technical organizational actions (Brazil, 2017).

\section{CONCLUSIONS}

It was concluded that the right side of the body presented higher values than the left side on the OCRA Checklist. In the minority of the tasks, the workers used a knife, and three tasks have not received a score related to the frequency of technical actions $(<30$ actions).

In most of the tasks, the presence of identical and repeated working gestures of the shoulder and/or elbow and/or wrist and/or hand were identified almost the entire time. The most frequent additional factor in the studied slaughterhouse was that the work pace was completely determined by machines. Most of the 
tasks received a score of 1 for shoulder, a score of 2 for elbow and wrist, and a score of 4 for the hand/fingers. A positive correlation was established between the result of the OCRA Checklist "without job rotation" and the score of the postures of the elbow, wrist and fingers, showing the predominance of manual tasks in slaughterhouses and the influence of these postures in risk assessment.

In the three conditions tested (with and without job rotation), the majority of the tasks presented moderate risk, and for "without job rotation", the number of tasks classified as moderate risk was smaller than in conditions "with job rotation" (tasks $>1 \mathrm{~h}$ and $<1 \mathrm{~h}$ ). Conversely, analyzing the scores of the three tasks of the OCRA Checklist conditions, there were differences between "without job rotation" and "with job rotation - tasks $>1 \mathrm{~h}$ ", as well as "without job rotation" and "with job rotation - tasks $<1 \mathrm{~h}$ ", with higher values in the work conditions "with job rotation".

Thus, the results of the risk using the OCRA Checklist method showed the inefficiency of the realization of rotations $>1 \mathrm{~h}$ and $<1 \mathrm{~h}$ compared to not carrying out job rotations. Despite this, some requirements requested by NR-36 have been met in most rotations of each sector, besides the alternation of the sitting and standing postures, postural requirements and monotony reduction, and half of the sectors met the reduction of carrying, handling and lifting of loads (mass). However, no sector has met the requirements related to the alternating muscle groups requested; the switching of tasks without requirements of repeatability and alternating with more comfortable environmental exposures; in addition to the reduction of static and dynamic efforts.

Finally, the difficulty of implementing efficient rotation due to particularities of the work in slaughterhouses was verified, such as: tasks with similar musculoskeletal requirements, pace imposed by machines, inability to perform rotations between different sectors (health and occupational constraints), the predominance of upper limb repetitive tasks with moderate and high risks, hindering the minimization of risks between the tasks of the rotation. Additionally, it is suggested that studies should be conducted to analyze worker satisfaction regarding the adoption of job rotations in slaughterhouses.

\section{REFERENCES}

ABNT. Associação Brasileira de Normas Técnicas. NBR ISO 11228-3 ergonomia - movimentação Manual - Parte 3: Movimentação e cargas leves e alta frequência de repetição. Rio de Janeiro: ABNT; 2014.
ABPA. Brazilian Association of Animal Protein. Annual Report 2017. São Paulo: ABPA; 2017 [cited 2017 Nov 20]. Available from: http://abpabr.com.br/storage/files/final_abpa_relatorio_anual_2017_ingles_web. pdf.

Arvidsson I, Balogh I, Hansson GA, Ohlsson K, Akesson I, Nordander C Rationalization in meat cutting-consequences on physical workload Applied Ergonomics 2012;43(6):1026-32

Asensio-Cuesta S, Diego-Mas JA, Canós-Darós L, Andrés-Romano C. A genetic algorithm for the design of job rotation schedules considering ergonomic and competence criteria. International Journal of Advanced Manufacturing Technology 2012;60(9):1161-74

Bernard BP. Musculoskeletal disorders and workplace factors: a critical review of epidemiologic evidence for work-related musculoskeletal disorders of the Neck, upper extremity, and Low Back. Cincinnati: National Institute for Occupational Safety and Health; 1997.

Brasil. Ministério do Trabalho e Emprego. Manual de Auxílio na Interpretação e Aplicação da Norma Regulamentadora n 36: Segurança e Saúde no Trabalho em Empresas de Abate e Processamento de Carnes e Derivados. Brasília: MTE; 2017 [cited 2017 Dec 15]. Available from: https://bibliotecaprt21.files.wordpress.com/2017/11/manual_da_ nr_36.pdf.

Brasil. Ministério do Trabalho e Emprego. Portaria MTE n. 555, de 18 de abril de 2013, Norma Regulamentadora 36. Segurança e Saúde no Trabalho em Empresas de Abate e Processamento de Carnes e Derivados. Brasília: MTE; 2013.

Buckle PW. Fortnightly review: work factors and upper limb disorders. BMJ 1997;315:1360-3.

Caso MA, Ravaioli M, Veneri L. Esposizione a sovraccarico biomeccanico degli arti superiori: la valutazione del rischio lavorativo nei macelli avicoli. Prev Oggi 2007;3:9-21

CEN. European Committee for Standardization. EN 1005-5, Safety of machinery - Human physical performance. Part 5: Risk assessment for repetitive handling at high frequency. Brussels: CEN; 2005.

Christensen H, Sogaard K, Pilegaard M, Olsen HB. The importance of the work/rest pattern as a risk factor in repetitive monotonous work. International Journal of Industrial Ergonomics 2000;25(4):367-73.

Claudon L, Marsot J. Effect of knife sharpness on upper limb biomechanical stresses - a laboratory study. International Journal of Industrial Ergonomics 2006;36:239-46.

Colombini D, Occhipinti E, Fanti M. Método Ocra para análise e a prevenção do risco por movimentos repetitivos: manual para a avaliação e a gestão do risco. Curitiba: Escola Ocra Brasiliana; 2014

Colombini D, Occhipinti E, Grieco A. Risk Assessment and Management of Repetitive Movements and Exertions of Upper Limbs Oxford: Elsevier; 2002.

Colombini D, Occhipinti E. Risultati della valutazione del rischio e do danno em gruppi di lavoratori esposti, em diversi comparti lavorativi, a movimenti e sforzi ripetuti degli arti superiori. La Medicina del Lavoro 2004:95:233-46.

EPM. Ergonomics of Posture and Movement. Mapping with Checklist [software]. 2013 Apr 29 [cited 2018 Jan 23]. Available from: http://www.epmresearch.org/index.php?fl=2\&op=mcs\&id cont $=837 \&$ idm $=837 \&$ moi $=837$

Filus R, Okimorto ML. The effect of job rotation intervals on muscle fatiguelactic acid. Work 2012;41(Suppl 1):1572-81.

Frazer M, Norman R, Wells R, Neumann P. The effects of job rotation on the risk of reporting low back pain. Ergonomics 2003;46(9):904-19. 
Game AM. Workplace boredom coping: Health, safety, and HR implications. Perspective Review 2007;36(5):701-21.

Guimarães LDM, Anzanello MJ, Renner JS. A learning curve-based method to implement multifunctional work teams in the Brazilian footwear sector. Applied Ergonomics 2012;43(3):541-7

Howarth SJ, Beach TA, Pearson AJ, Callaghan JP. Using sitting as a component of job rotation strategies: are lifting/lowering kinetics and kinematics altered following prolonged sitting. Applied Ergonomics 2009;40(3):433-9.

Huang SH, Pan YC. Ergonomic job rotation strategy based on an automated RGB-D anthropometric measuring system. Journal Manufacturing Systems 2014;33(4):699-710.

ISO. International Organization for Standardization. ISO 11228-3:2007. Ergonomics -- Manual handling -- Part 3: Handling of low loads at high frequency. Geneva: ISO; 2007.

Kilbom A. Repetitive work of the upper extremity: part I-the scientific basis (knowledge base) for the guide. International Journal of Industrial Ergonomics 1994;14(1-2):59-86

Konz S. Work design: Industrial ergonomics. Worthington $(\mathrm{OH})$ : Publishing Horizons; 1990.

Mathiassen, SE. Diversity and variation in biomechanical exposure: what is it, and why would we like to know? Applied Ergonomics 2006;37:41927

Michalos G, Makris S, Rentzos L, Chryssolouris G. Dynamic job rotation for workload balancing in human based assembly systems. CIRP Journal of Manufacturing Science and Technolpgy 2010;2(3):153-60.

Occhipinti E, Colombini D, Occhipinti M. Metodo OCRA: messa a punto di una nuova procedura per l'analisi di compiti multipli con rotazioni infrequenti. La Medicina del Lavoro 2008;99(3):234-41.

Occhipinti E, Colombini D. Updating reference values and predictive models of the OCRA method in the risk assessment of workrelated musculoskeletal disorders of the upper limbs. Ergonomics 2007; 50:1727-39.

OSHA. Occupational Safety and Health Administration. Prevention of musculoskeletal injuries in poultry processing. Washington (DC): OSHA; 2013 [cited 2018 Jan 23]. Available from: https://www.osha. gov/Publications/OSHA3213.pdf.

Padula RS, Comper MLC, Sparer EH, Dennerlein JT. Job rotation designed to prevent musculoskeletal disorders and control risk in manufacturing industries: a systematic review. Applied Ergonomics 2017;58:386-97.

Punnett L, Wegman DH. Work-related musculoskeletal disorders: the epidemiologic evidence and the debate. Journal of Electromyography Kinesiology 2004;14(1):13-23.
Rasotto C, Bergamin M, Simonetti A, Maso S, Bartolucci GB, Ermola A et al. Tailored exercise program reduces symptoms of upper limb work-related musculoskeletal disorders in a group of metalworkers: A randomized controlled trial. Man Therapy 2015;20(1):56-62.

Reis DC, Moro ARP, Ramos E, Reis PF. Upper Limbs Exposure to Biomechanical Overload: Occupational Risk Assessment in a Poultry Slaughterhouse. In: Goonetilleke, R, Karwowski W, editors. Advances in physical ergonomics and human factors. Orlando: Springer International Publishing; 2016. v. 489. p. 275-82.

Reis DC, Ramos E, Reis PF, Hembecker, PK, Gontijo LA, Moro ARP. Assessment of risk factors of upper-limb musculoskeletal disorders in poultry slaughterhouse. Procedia Manufacturing 2015a;3:4309-14.

Reis DC, Reis, PF, Moro ARP. Assessment of risk factors of musculoskeletal disorders in poultry slaughterhouse. In: Azeres P, Baptista JS, Barroso MP, Carneiro P, Cordeiro P, Costa N, et al., editors. Proceedings Book of the International Symposium on Occupational Safety and Hygiene SHO2015. Guimarães, Portugal: Sociedade Portuguesa de Segurança e Higiene Ocupacionais; 2015b. p. 294-6.

Reis DC, Tirloni AS, Ramos E, Moro ARP. G3-2-Assessment of Risk Factors of Upper-limb Musculoskeletal Disorders in a Chicken Slaughterhouse. Japanese Journal of Ergonomics 2017;53:S458-S61.

Reis PF, Peres LS, Tirloni AS, Reis DC, Estrázulas JA, Rossato M, Moro ARP. Influence of anthropometry on meat-packing plant workers: an approach to the shoulder joint. Work 2012;41(Suppl 1):4612-17.

Rodriguez AC, Barrero LH. Job rotation: Effects on muscular activity variability. Applied Ergonomics 2017;60:83-92

Silverstein BA, Fine LJ, Armstrong TJ. Hand wrist cumulative trauma disorders in industry. Occupational Environmental Medicine 1986;43(11):779-84

Tirloni AS, Reis DC, Santos JB, Reis PF, Barbosa A, Moro ARP. Body discomfort in poultry slaughterhouse workers. Work 2012;41(Suppl 1):2420-5.

Toulouse G, Richard JG. Slaugterhouses. In: Karwowski W, editor. International encyclopedia of ergonomics and human factors. 2nd ed. Boca Raton (FL): CRC Press; 2006. v. 3. p. 1588-90

Van der Windt DA, Thomas E, Pope DP, De Winter AF, Macfarlane GJ, Bouter LM, et al. Occupational risk factors for shoulder pain: a systematic review. Occupational Environmental Medicine 2000;57:433-42.

Zawiah S, Taha, Z. The effect of job organizational factors on job satisfaction in two automotive industries in Malaysia. Journal Human Ergology 2007:36(2):63-8 
